\title{
Extensive Posttranscriptional Deletion of the Coding Sequences for Part of Nucleotide-binding Fold 1 in Respiratory Epithelial mRNA Transcripts of the Cystic Fibrosis Transmembrane Conductance Regulator Gene Is Not Associated with the Clinical Manifestations of Cystic Fibrosis
}

\author{
Chin-Shyan Chu, ${ }^{\star}$ Bruce C. Trapnell, ${ }^{\star}$ Sheila M. Curristin, ${ }^{\star}$ Garry R. Cutting, ${ }^{\star}$ and Ronald G. Crystal ${ }^{\star}$ \\ * Pulmonary Branch, National Heart, Lung, and Blood Institute, National Institutes of Health, Bethesda, Maryland 20892; \\ and ${ }^{\ddagger}$ Department of Pediatrics and Center for Medical Genetics, Johns Hopkins Hospital, Baltimore, Maryland 21205
}

\begin{abstract}
Cystic fibrosis (CF) is a recessive hereditary disorder, requiring both parental cystic fibrosis conductance transmembrane regulator (CFTR) genes to carry mutations for clinical disease to manifest, i.e., only $\mathbf{5 0 \%}$ of normal CFTR gene expression is required to maintain a normal phenotype. To help define the minimum amount of normal CFTR gene expression necessary to maintain normalcy, we have capitalized on our prior observation (Chu, C.-S., B. C. Trapnell, J. J. Murtagh, Jr., J. Moss, W. Dalemans, S. Jallat, A. Mercenier, A. Pavirani, J.-P. Lecocq, G. R. Cutting, et al. 1991. EMBO [Eur. Mol. Biol. Organ.] J. 10:1355-1363) that normal individuals can have up to 66\% of bronchial CFTR mRNA transcripts that are missing exon 9 , a region representing $21 \%$ of the sequence coding for the critical nucleotide (ATP)-binding fold 1 (NBF1) of the predicted CFTR protein. The study population included 78 individuals with no prior diagnosis of CF. Evaluation of bronchial epithelial cells (obtained by bronchoscopy) revealed that exon 9 was variably deleted in all individuals. Remarkably, there were four individuals, all $\geq 35 \mathrm{yr}$, in whom bronchial epithelial cells exhibited 73, 89, 90, and 92\% CFTR transcripts with inframe deletion of exon 9 , respectively, despite normal sweat $\mathrm{Cl}^{-}$and no clinical manifestation of $\mathrm{CF}$. In the context that only 8\% or less of bronchial CFTR transcripts need exon 9 to maintain normal airway function, these observations strongly suggest that either exon 9 is not necessary for CFTR structure and /or function or that only a very small fraction of bronchial epithelial cells need to express normal CFTR mRNA transcripts with exon 9 to perform the function of CFTR sufficient to maintain a normal phenotype in vivo. (J. Clin. Invest. 1992. 90:785-790.) Key words: bronchial epithelium • exon • splicing - polymerase chain reaction
\end{abstract}

\section{Introduction}

Cystic fibrosis $(\mathrm{CF})^{1}$ is a common lethal autosomal recessive disorder of Caucasians with major manifestations localized to

Address reprint requests to Pulmonary Branch, Building 10, Room 6DO3, National Heart, Lung, and Blood Institute, National Institutes of Health, Bethesda, MD 20892.

Received for publication 24 October 1991 and in revised form 5 March 1992.

1. Abbreviations used in this paper: $\mathrm{CF}$, cystic fibrosis; CFTR, CF transmembrane conductance regulator; CT, computerized tomography; NBF, nucleotide-binding fold; PCR, polymerase chain reaction.

The Journal of Clinical Investigation, Inc.

Volume 90, September 1992, 785-790 the epithelium of the tracheobronchial tree $(1,2)$. The $\mathrm{CF}$ transmembrane conductance regulator (CFTR) gene, located on the long arm of human chromosome 7 at q31-q32, is a 27-exon gene spanning over $250 \mathrm{~kb}$ (3-6). The structure of the putative CFTR gene product is a 1480-residue glycoprotein organized in two repeated motifs, each consisting of a membrane-spanning domain with six membrane-spanning segments, and one nucleotide (ATP)-binding fold (NBF), separated by a large polar $\mathrm{R}$ (regulatory) domain which contains multiple potential phosphorylation sites (Fig. $1 A$ ).

The amino-terminal NBF (NBF1), a 154-residue domain coded by exons $9-12$, is believed to play a critical role in the structure and/or function of the CFTR protein (4, 7-12). The initial $21 \%$ of NBF1, coded by the $183-$ bp exon 9 , contains a highly conserved ATP-binding motif homologous to Walker motif $A(4,13)$. There are two naturally occurring mutations reported in exon 9 (A455E and G458V) (Fig. $1 B$ ); both are associated with the clinical manifestations of cystic fibrosis ( 9 , 14). Further, when a mutation is generated in vitro at the $3^{\prime}$ end of exon $9(\mathrm{~K} 464 \mathrm{M})$, the protein product of the mutated cDNA is not able to direct cells to secrete halide in response to cAMP in a fashion typical of the function of the normal CFTR $(10,11)$.

Given the apparent important role for NBF1, we were surprised to observe that among 12 normal individuals with no clinical manifestation of CF, up to $66 \%$ of CFTR mRNA transcripts in bronchial epithelium had an in-frame deletion of exon 9- CFTR transcripts, likely due to posttranscriptional splicing of the primary transcripts of CFTR gene (15). Capitalizing on this observation to help define the minimum amount of normal CFTR mRNA necessary to maintain a normal phenotype in vivo, we have quantified the proportion of exon $9^{-}$ CFTR transcripts in the bronchial epithelium of 78 individuals with no history of CF. Among this group, we have found a subgroup with extraordinarily high proportion of exon $9^{-}$transcripts, yet no evidence of the clinical manifestations of $\mathrm{CF}$.

\section{Methods}

Study population. A total of 78 individuals $\geq 19 \mathrm{yr}, 75$ individuals with normal CFTR genotype at $\mathrm{Phe}^{508}$ and three individuals heterozygous for $\Delta \mathrm{F} 508$ (the loss of $\mathrm{Phe}^{508}$ due to three base pair deletion), were evaluated. These individuals were randomly selected among individuals admitted to the Pulmonary Branch, National Heart, Lung, and Blood Institute, Clinical Service and undergoing bronchoscopy for the evaluation of chronic lung disease and from a group of normal volunteers. None had a prior diagnosis of CF. The entire study included: normal $(n=51)$, idiopathic pulmonary fibrosis $(n=10)$, chronic bronchitis $(n=5), \alpha \mathrm{l}$-antitrypsin $(\alpha \mathrm{lAT})$ deficiency $(n=4)$, interstitial lung disease associated with connective tissue disorder $(n=2)$, sarcoidosis $(n=2)$, asbestosis $(n=3)$, and histiocytosis $\mathrm{X}(n=1)$. 
A

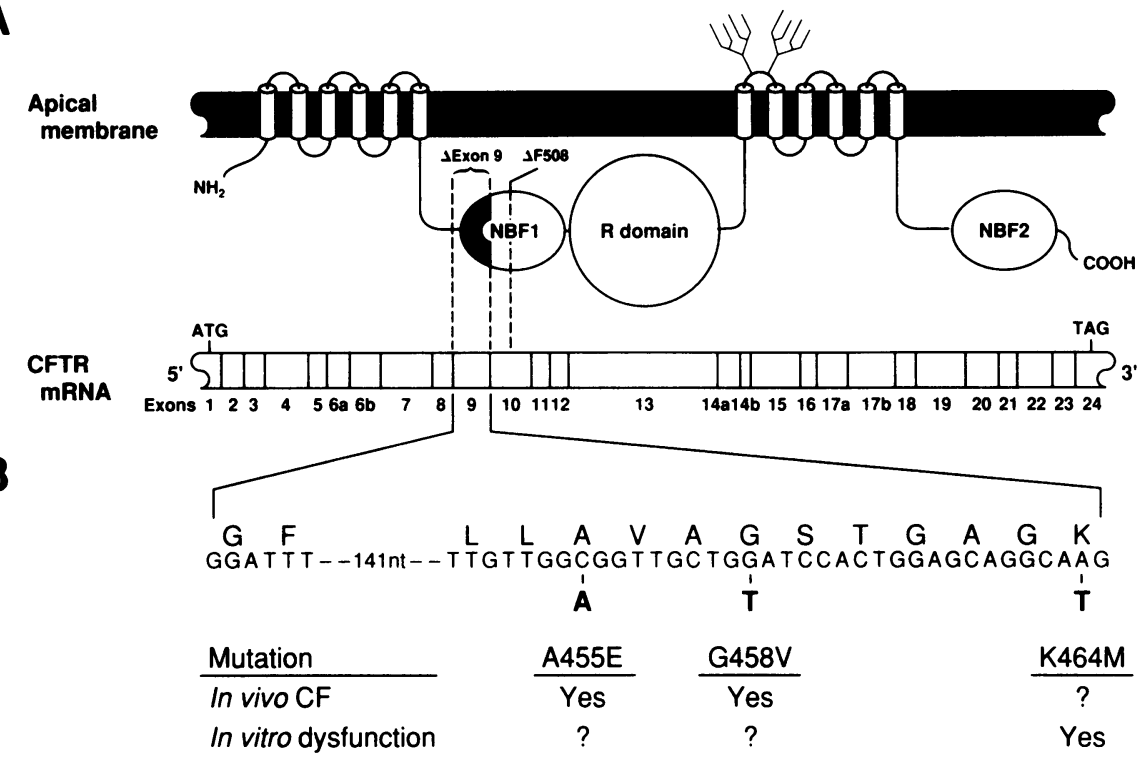

Figure 1. Predicted structure of the CFTR protein, exon distribution of CFTR mRNA transcripts, and mutations in exon 9 known to cause cystic fibrosis and/or dysfunction of the CFTR gene product. $(A)$ Schematic of the putative CFTR protein and the known structure of mature 27-exon CFTR mRNA transcripts. The predicted domains of CFTR are aligned above the mRNA exons encoding each region and include membrane-spanning domains (depicted as cylinders in the apical membrane), cytoplasmic nucleotide binding fold 1 (NBF1), R domain, and nucleotide binding fold 2 (NBF2). The two potential extracellular $N$-glycosylation sites between membrane-spanning segment 7 and 8 are indicated. If exon 9 is deleted in CFTR mRNA, the shaded portion of NBF1 would be deleted (indicated as $\Delta$ exon 9 ). The most common mutation of CFTR gene $(\triangle F 508)$ is in exon 10 which is within NBF1. The start codon (ATG, exon 1) and stop codon (TAG, exon 24) are shown. (B) Mutations of exon 9 associated with CF and/or dysfunction of the CFTR protein product in vitro. Shown is the partial nucleotide sequence of exon 9 of CFTR gene; the predicted amino acid sequence (single letter code) is shown above the second base of the corresponding codon. There are two naturally occurring mutations associated with $\mathrm{CF}$ ( A455E, G458V) (9, 14). One mutation generated in vitro by site directed mutagenesis $(\mathrm{K} 464 \mathrm{M})$ is associated with dysfunctional CFTR gene product as evidenced by the lack of cAMP-activated iodide efflux $(10,11)$.

Of the entire group, quantification of bronchial epithelial exon $9^{-}$ CFTR transcripts demonstrated that in four individuals (indicated as individuals A-D throughout the text), $>66 \%$ (the highest level previously observed among 12 normal individuals [15]) of the total bronchial epithelial CFTR mRNA transcripts were exon $9^{-}$. These four individuals were reevaluated for a history of frequent sputum production or symptoms of pancreatic insufficiency, standard sweat $\mathrm{Cl}^{-}$testing (16), chest $x$ ray, lung function testing (17), and bronchoalveolar lavage (18) (Table I). Normal individual B and the two individuals with evidence of lung disease (individuals $\mathrm{C}, \mathrm{D}$ ) also had computerized tomography $(\mathrm{CT})$ scanning of the chest.

Individual A, a 49-yr-old female, was completely normal. Individual B, a 51-yr-old female, had no evidence of lung disease, but did have alopecia since birth, as well as hypertension, hypothyroidism, and hyperlipidemia. Individual $\mathrm{C}$, a 35 -yr-old male, had the $\mathrm{Z}$ homozygous form of $\alpha$ l-antitrypsin deficiency (serum $\alpha$ lAT level $4.7 \mu \mathrm{M}$, normal range $20-53 \mu \mathrm{M}$ ), with evidence of emphysema typical of $\alpha \mathrm{IAT}$ deficiency $(19,20)$. Individual D, a 52-yr-old female and sister of individual B, had idiopathic pulmonary fibrosis diagnosed by the usual clinical criteria including open lung biopsy (21). Among individuals A-D, none had a history of frequent sputum production, chronic respiratory infections, or pancreatic insufficiency; all had normal sweat $\mathrm{Cl}^{-}$tests ( $<60 \mathrm{meq} /$ liter $[1,16])$ and a normal CFTR genotype at $\mathrm{Phe}^{508}(4,5)$.

Quantification of CFTR MRNA transcripts with and without exon 9. Bronchial epithelial cells were obtained as previously described from mainstem or lobar bronchi by fiberoptic bronchoscopy, using a standard cytology brush (Microvasive Inc., Watertown, MA) (15). The cells were immediately suspended in RPMI 1640 (Whittaker Bioproducts, Walkersville, MD), collected by centrifugation, and lysed in $4 \mathrm{M}$ guanidinium thiocyanate, $25 \mathrm{mM}$ sodium citrate, $\mathrm{pH} 7.0,0.5 \%$ sarcosyl, $0.1 \mathrm{M} \beta$-mercaptoethanol. The quantification of CFTR mRNA transcripts in bronchial epithelium with and without exon 9 was performed as previously described (15). Briefly, total RNA of the bronchial epithelial cells was extracted and converted to cDNA. The CFTR mRNA transcripts (after conversion to cDNA ) were amplified by polymerase chain reaction (PCR) using the DNA Thermal Cycler and recombinant Taq DNA polymerase (AmpliTaq; Perkin-Elmer Cetus Instruments, Norwalk, CT) (22). The amplification was performed for
10 cycles $\left(94^{\circ}-20 \mathrm{~s}, 64^{\circ}-20 \mathrm{~s}, 72^{\circ}-60 \mathrm{~s}\right)$ with sense primer CF37 (5'CAGAACTGAAACTGACTCGGAAGG-3', located in exon 7) and antisense primer CF31 (5'-TCTTTCTCTGCAAACTTGGAGATG3 ', located in exon 11). An aliquot of the first PCR reaction was used for further "nested" amplification under similar conditions for 25-30 cycles, except using sense primer CF85 (5'-ACAAACATGGTATGACTCTCTTGG-3', located in exon 7) and antisense primer CF3 (5'-CTTCTAGTTGGCATGCTTTGATGACGCTTC-3', located in exon 10). An aliquot of the nested PCR product of each sample was evaluated by Southern analysis using a $125-\mathrm{bp}{ }^{32} \mathrm{P}$-labeled nested CFTR cDNA probe located in exon 10 ("exon 10" probe) (15). The bands of the larger fragment ( $509 \mathrm{bp}$, CFTR mRNA with exon 9) and the smaller fragment ( $326 \mathrm{bp}$, CFTR mRNA without exon 9) of each sample on the autoradiogram were scanned by LKB 2202 UltraScan laser densitometer (Pharmacia-LKB Biotechnology Inc., Piscataway, $\mathrm{NJ}$ ), and the relative amount of CFTR transcripts with exon 9 (exon $9^{+}$CFTR transcripts) and without exon 9 (exon $9^{-}$CFTR transcripts) were calculated (as percentage of total CFTR transcripts) using the total densitometric units of both transcripts as $100 \%$.

Nucleotide sequence of CFTR $m R N A$ transcripts of bronchial epithelial cells. The nucleotide sequence of CFTR transcripts with and without exon 9 was performed as described previously (15). Briefly, total RNA of bronchial epithelial cells was extracted and converted to cDNA. A portion of the CFTR CDNA was amplified with primers CF37 and CF31, then CF85 and CF3 as described above and size fractionated by agarose gel electrophoresis. The fragments of exon $9^{+}$and exon $9^{-}$transcripts were excised from the agarose gel and purified. The exon $9^{-}$transcripts were further amplified with primers $\mathrm{CF} 85$ and CF3 $-\mathrm{O}$ ("-O" indicates that the primer was biotinylated). Biotinylated single-stranded CFTR transcripts (containing CF3-O) were prepared by using a magnetic particle concentrator and Dynabeads M- 280 streptavidin (Dynal Inc., Great Neck, NY), and sequenced with CF85. The exon $9^{+}$transcripts were sequenced using the same technique except using two separate sets of PCR and sequencing primers: ( $a$ ) PCR with CF85 and CF84-O (5'-CTGCTCCAGTGGATCCAGCAACCG-3', located in exon 9) and sequencing with CF85; and (b) PCR with CF39 (5'-CTTCAGTAATTTCTCACTTCTTGG-3', located in exon 9) and CF3-O and sequencing with CF39. 
Table I. Characteristics of Individuals with High Proportion of Bronchial Epithelial CFTR mRNA Transcripts without Exon 9

\begin{tabular}{|c|c|c|c|c|}
\hline \multirow[b]{2}{*}{ Characteristics $^{\ddagger}$} & \multicolumn{4}{|c|}{ Individual $^{*}$} \\
\hline & A & B & $\mathrm{C}$ & $\mathrm{D}$ \\
\hline Age $(y r)$ & 49 & 51 & 35 & 52 \\
\hline Sex & Female & Female & Male & Female \\
\hline Genotype at Phe $\mathrm{Pho}^{508}$ & Normal/normal & Normal/normal & Normal/normal & Normal/normal \\
\hline Pulmonary status & Normal & Normal & $\begin{array}{c}\alpha 1 \text {-antitrypsin } \\
\text { deficiency }\end{array}$ & $\begin{array}{l}\text { Idiopathic pulmonary } \\
\text { fibrosis }\end{array}$ \\
\hline Sweat $\mathrm{Cl}^{-}$(meq/liter) & 16 & 16 & 19 & 34 \\
\hline Chest $\mathrm{x}$ ray & Normal & Normal & Hyperinflation & $\begin{array}{l}\text { Reticulonodular } \\
\text { infiltrates }\end{array}$ \\
\hline Chest CT & $\mathrm{ND}^{\S}$ & Normal & $\begin{array}{l}\text { Emphysema; } \\
\text { no bronchiectasis }\end{array}$ & $\begin{array}{l}\text { Interstitial } \\
\text { infiltrates; } \\
\text { no bronchiectasis }\end{array}$ \\
\hline Sputum production & No & No & No & No \\
\hline \multicolumn{5}{|c|}{ Lung function (percent predicted) } \\
\hline FVC & 97 & 118 & 105 & 58 \\
\hline FEV1 & 94 & 128 & 46 & 71 \\
\hline FEV1/FVC & 96 & 108 & 44 & 118 \\
\hline TLC & 105 & 115 & 142 & 58 \\
\hline DLCO & 102 & 133 & 59 & 52 \\
\hline \multicolumn{5}{|l|}{ Bronchoalveolar lavage } \\
\hline Percent fluid recovered & 46 & 60 & 20 & 56 \\
\hline Total cells recovered $/ \mathrm{ml}$ & $192 \times 10^{3}$ & $124 \times 10^{3}$ & $142 \times 10^{3}$ & $88 \times 10^{3}$ \\
\hline Macrophage (\%) & 94 & 87 & 91 & 66 \\
\hline Neutrophil (\%) & 1 & 2 & 9 & 2 \\
\hline Lymphocyte (\%) & 5 & 11 & 1 & 32 \\
\hline Eosinophil (\%) & 0 & 0 & 0 & 1 \\
\hline Culture & $\mathrm{ND}^{\S}$ & $\mathrm{ND}^{\S}$ & Normal" & Normal ${ }^{\|}$ \\
\hline Pancreatic insufficiency & No & No & No & No \\
\hline
\end{tabular}

* Individuals A-D are the same as in Fig. 2, respectively; individuals B and D are sisters. ${ }^{\ddagger}$ FEV1, forced expiratory volume in $1 \mathrm{~s}$; FVC, forced vital capacity; TLC, total lung capacity; DLCO, carbon monoxide diffusion capacity. ${ }^{\S} \mathrm{ND}$, not done. "Normal oropharyngeal flora.

CFTR mRNA transcript level of bronchial epithelium. To investigate whether individuals with very high bronchial epithelial exon $9^{-}$ CFTR mRNA transcripts upregulated their bronchial epithelial total CFTR mRNA transcripts, bronchial epithelial cells were obtained by

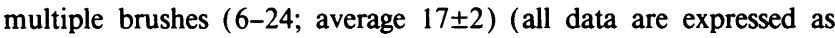
mean \pm SEM and all statistical comparisons were made using the twotailed Student's $t$ test unless noted otherwise) with $1 \mathrm{~mm}$ cytology brush by fiberoptic bronchoscopy from three individuals (B-D) with very high bronchial epithelial exon 9- CFTR mRNA transcripts (89$92 \%$ ) and five individuals with lower bronchial epithelial exon $9^{-}$transcripts (6-30\%; average $17 \pm 4 \%$ ). Total RNA of bronchial epithelial sample from each individual was extracted by guanidinium thiocyanate- $\mathrm{CsCl}$ method (23), evaluated by northern analysis ( $5 \mu \mathrm{g} \mathrm{RNA}$ / lane) using QuikHyb rapid hybridization solution (Stratagene Inc., La Jolla, CA) and a ${ }^{32} \mathrm{P}$-labeled 4.5-kb human CFTR cDNA probe (pTG4976) (24). The CFTR mRNA transcript level of each sample was quantified by using Phosphor-Imager (Molecular Dynamics, Sunnyvale, CA ). As a control, glyceraldehyde-3-phosphate dehydrogenase (GAPDH) mRNA transcript level of each sample was evaluated by using a ${ }^{32}$ P-labeled 1.0-kb human GAPDH cDNA probe (pPB312) (25). After being adjusted with GAPDH mRNA transcript level of each individual sample, the relative level of CFTR mRNA transcripts in bronchial epithelial cells of each sample was quantified by using the mean of relative total CFTR mRNA levels of five individuals with lower exon $9^{-}$mRNA transcripts as $100 \%$.

Nucleotide sequence of intron 8/exon 9 splice acceptor site of CFTR gene. Human genomic DNA from individuals $\mathrm{A}-\mathrm{H}$ was extracted from blood leukocytes, amplified by PCR with specific primer pairs (includ- ing one biotinylated primer in some PCR reactions), prepared for single-strand DNA by using a magnetic particle concentrator and Dynabeads M-280 streptavidin (Dynal Inc.), and sequenced by the dideoxy chain-termination method (15). Briefly, the sequence of intron $8 /$ exon 9 splice acceptor site of the coding strand DNA was determined by: ( $a$ ) first PCR with sense primer CFIl (5'-TTGATAATGGGCAAATATCTTAG- $3^{\prime}$, located in intron 8 ) and antisense primer CFI2 (5'AAGATACAGTGTTGAATGTGGTG-3', located in intron 9); (b) second PCR with CFI3-O(5'-TTAGATCATGTCCTCTAGAAACCG-3', located in intron 8) and CFI20 (5'-ACATTCTCCTAATGCTCATGTAAG-3', located in intron 9); and (c) sequencing with CF38 (5'GAAATTAATATCTTTCAGGACAGG-3', located in exon 9). The sequence of the noncoding strand DNA in the same region was determined by: $(a)$ first PCR with CFI1 and CFI2; $(b)$ second PCR with CFI3 and CFI6-O (5'-AAGAGACATGGACACCAAATTAAG-3', located in intron 9); (c) sequencing with CFI25 (5'-TGTATACAGTGTAATGGATCATGG-3', located in intron 8).

\section{Results and Discussion}

Evaluation of the proportion of exon $9^{-}$CFTR transcripts in bronchial epithelial cells of the entire study group demonstrated a broad range (Figs. 2 and 3 ). On the average, $32.0 \pm 19.7 \%$ (mean \pm standard deviation) of CFTR transcripts were missing exon 9 . Of the 78 individuals, 6 had $<10 \%$ exon $9^{-}$transcripts. Strikingly, 4 had $>66 \%$ bronchial epithelial 


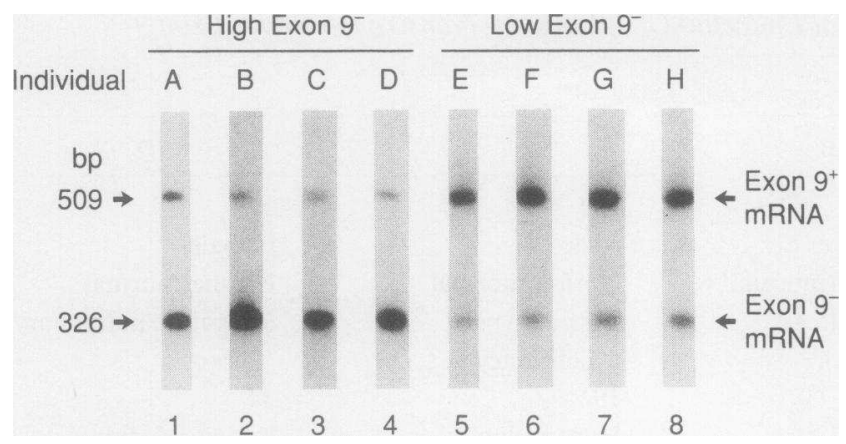

Figure 2. Quantification of the relative amount of exon 9- CFTR mRNA transcripts in human bronchial epithelial cells. Bronchial epithelial cell total RNA was extracted, converted to cDNA, amplified by PCR, subjected to Southern analysis using a ${ }^{32} \mathrm{P}$-labeled exon 10 probe, and the relative proportion of exon $9^{+}$and exon $9^{-}$mRNA transcripts quantified using laser densitometry on the resulting autoradiograms. Exon $9^{+}$mRNA transcripts yield a 509-bp PCR product while the exon $9^{-}$transcripts yield a 326-bp product; for details, see Methods and reference 15 . Lanes 1-4 represent the four individuals with high proportion of exon $9^{-}$transcripts; see Table I for details of each individual. Lanes 5-8 are typical examples of the rest of the study group, with exon $9^{-}$transcripts usually $<50 \%$ of the total.

mRNA transcripts that were missing exon 9 (66\% is the highest level previously observed among 12 normal individuals [15]).

Of these four individuals, none had evidence of the clinical manifestations of CF (Table I). There was no history of frequent sputum production, chronic respiratory infections, heat intolerance, pancreatic insufficiency, malnutrition, hepatic dysfunction, or infertility in any individual. Individual $\mathrm{C}$ had the classic manifestations of $\alpha \mathrm{lAT}$ deficiency with emphysema and individual $\mathrm{D}$ had the classic manifestations of idiopathic pulmonary fibrosis; both had been referred to the Pulmonary Branch Clinical Service for evaluation for these specific conditions. Chest CT scans of individuals $C$ and $D$ showed typical evidence of emphysema and fibrosis, respectively, but no evidence of bronchiectasis. For all four individuals, when the

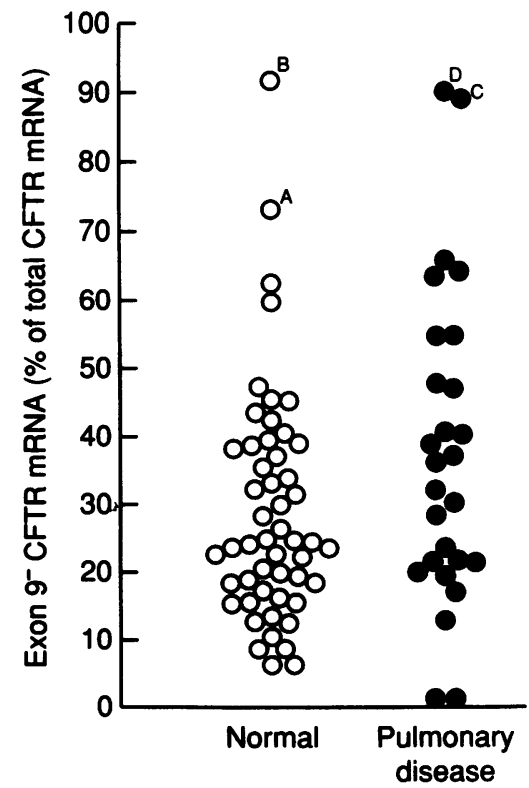

Figure 3. Proportion of exon 9- CFTR mRNA transcripts in bronchial epithelial cell from normals and individuals with pulmonary diseases other than cystic fibrosis. The relative proportion of exon $9^{-}$ mRNA transcripts was quantified as described in Fig. 2. Each sample is represented by a separate symbol. The superscripts $A-D$ indicate samples from individuals $A-D$
CFTR mRNA transcripts of bronchial epithelial cells (after conversion to cDNA) were amplified in the region encompassing exons $7-10$ by polymerase chain reaction, two different sized fragments were present (Fig. 2). The size difference between these two amplified fragments ( $509 \mathrm{bp}$ and $326 \mathrm{bp}$ ) was the same as the size of exon $9(183 \mathrm{bp})$. As previously observed for exon 9 deletion from CFTR transcripts in bronchial epithelial cells (15), sequence analyses revealed that the 326-bp fragment had a complete deletion of exon 9 (exon $9^{-}$transcripts), with in-frame joining of exon 8 to exon 10; and the 509-bp fragment contained the entire coding sequence of exon 9 ( exon $9^{+}$transcripts).

Quantitative analysis with an exon 10-specific probe demonstrated that individuals A-D had very high proportion of exon 9-CFTR mRNA transcripts (Fig. 2). Strikingly, the bronchial CFTR transcripts of all four individuals were mostly exon $9^{-}$, with proportions of exon $9^{-}$transcripts $73,92,89$, and $90 \%$ (individuals A-D respectively); comparison of the percent exon $9^{-}$transcripts to the sweat $\mathrm{Cl}^{-}$concentration showed no relationship between the two parameters (Fig. 4). As a control to insure the consistency of this observation, one individual (D) was reevaluated by bronchoscopy and brushing 10-wk after the initial analysis. Using fresh reagents, this analysis demonstrated that $95 \%$ of bronchial CFTR transcripts were exon $9^{-}$, compared to $90 \%$ in the initial analysis. This is consistent with our previous observation that the percentage of exon $9^{-}$ CFTR transcripts in bronchial epithelium of the same individuals did not change significantly by separate evaluations (15).

The major clinical manifestations of $\mathrm{CF}$ are localized to the lung, where accumulation of thick mucous secretions is associated with recurrent infections and chronic obstructive lung disease leading to bronchiectasis, respiratory failure, and death $(1,2)$. Current data suggest that individuals with cystic fibrosis have defective regulation of apical membrane $\mathrm{Cl}^{-}$channels in airway epithelial cells (26-30). The CFTR-associated $\mathrm{Cl}^{-}$ channel cannot be activated by protein kinase $\mathrm{C}$ or cAMP-dependent protein kinase in $\mathrm{CF}$ as in normals (27-30), although the cells can be activated to secrete $\mathrm{Cl}^{-}$by $\mathrm{Ca}^{++}$through the multifunctional $\mathrm{Ca}^{++}$calmodulin-dependent protein kinase

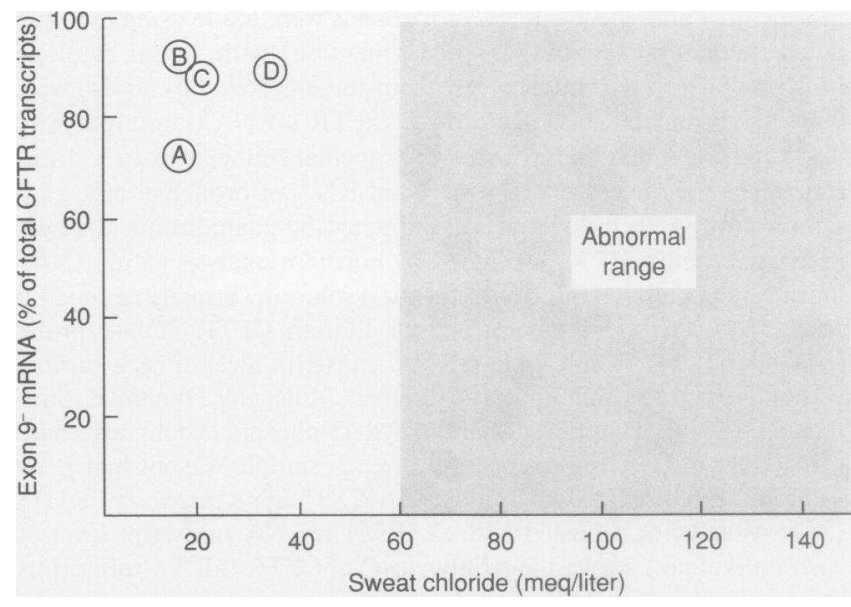

Figure 4. Proportion of exon 9- CFTR mRNA transcripts among all CFTR transcripts in bronchial epithelial cells from individuals $A-D$. The data are presented as a single data point for each individual (indicated by a letter corresponding to Fig. 2, 3, and Table I). Normal sweat $\mathrm{Cl}^{-}$values are $<60 \mathrm{meq} /$ liter. 
pathway (31). The available evidence strongly suggests that the CFTR functions itself as a $\mathrm{Cl}^{-}$channel $(12,32,33)$.

The putative structure of CFTR predicts that it belongs to the ATP-binding cassette superfamily of transport proteins including several bacterial exporters, P-glycoprotein associated multidrug resistance in mammalian tumors, and the STE6 gene product that mediates export of yeast a-factor mating pheromone $(4,7)$. While the CFTR protein without $R$ domain can function as a $\mathrm{Cl}^{-}$channel (albeit in a nearly constitutive fashion ) $(34,35), N B F 1$ is believed to be critical for any CFTR function. The NBF1 of CFTR, encoded by sequences of exons 9-12, contains two short highly conserved ATP-binding motifs homologous to Walker motifs $\mathrm{A}$ and $\mathrm{B}$, which are important in providing the energy for substrate accumulation $(4,7,13)$. There have been more CF-associated mutations, including the most common mutation $\triangle \mathrm{F} 508$, found in NBF1 than any other domain of CFTR, suggesting NBF1 plays an important role in the expression of the CFTR gene $(5,8-11,14,36,37)$. Exon 9 codes for the first $21 \%$ of NBF1 and mutations in this region are associated with clinical CF (A455E, G458V) or dysfunctional chloride channels in vitro $(\mathrm{K} 464 \mathrm{M})(9-11,14)$, suggesting that exon 9 is important to CFTR structure and/or function. In the context of these considerations, it is very unlikely that CFTR could function normally without the sequences encoded by the entire exon 9 . Surprisingly, the four individuals described in this study had no evidence of CF, despite having bronchial epithelial cells with $73,89,90$, and $92 \%$ exon $9^{-}$CFTR mRNA transcripts respectively, i.e., even with only $8 \%$ bronchial epithelial cell CFTR transcripts containing exon 9, there is still no clinical evidence of CF. Importantly, individuals with very high bronchial epithelial exon 9- CFTR mRNA transcripts did not upregulate their total CFTR mRNA transcripts in bronchial epithelium. In this regard, the total CFTR mRNA transcript levels of three individuals (B-D) with very high bronchial epithelial exon $9^{-}$transcripts (89-92\%) and five individuals with lower exon $9^{-}$transcripts (6-30\%; mean $17 \pm 4 \%$ ) were similar. Using GAPDH mRNA transcript level of each individual as control, the bronchial epithelial total CFTR mRNA level of the very high exon $9^{-}$transcripts group was $138 \pm 29 \%$ of the low exon $9^{-}$transcripts group ( $100 \pm 20 \%)$; and the difference between two groups was not significant $(P=0.31)$. In the context that human bronchial epithelial cells transcribe the CFTR gene at a low rate (38) and contain only an average of 1-2 CFTR mRNA transcripts per cell (39), these observations are consistent with two possibilities: (a) exon 9 is not necessary for CFTR structure and/or function; or $(b)$ only a small fraction of bronchial epithelial cells need to express normal CFTR mRNA transcripts to maintain a normal phenotype in vivo. If exon 9 is necessary for CFTR function, with 1-2 CFTR mRNA transcripts per cell (39) and 8\% exon $9^{-}$CFTR transcripts in bronchial epithelium, then at most, only $8-16 \%$ bronchial epithelial cells need to express normal exon $9^{+}$CFTR mRNA transcripts to maintain a normal phenotype. Consistent with the second alternative, recent studies by Johnson et al. (40) suggest that only $10 \%$ of respiratory epithelial cells derived from an $\Delta F 508$ homozygous individual need to be corrected to restore normal phenotypic function to CF airway epithelium in vitro, possibly because of cell-cell communication via gap junctions. Given the available technology, it is not possible to quantify the levels of functional CFTR protein in bronchial epithelial samples of the study population. However, it is likely that functional CFTR
Table II. Length of Polythymidine (polyT) Tract at the Intron 8/ exon 9 Splice Acceptor Site of Individuals $A-H^{*}$

\begin{tabular}{ccc}
\hline $\begin{array}{c}\text { Study } \\
\text { individual }\end{array}$ & $\begin{array}{c}\text { Exon } 9^{-} \text {mRNA (percentage of } \\
\text { total CFTR transcripts) }\end{array}$ & $\begin{array}{c}\text { PolyT tract at the } \\
\text { intron } 8 / \text { exon } 9 \text { SAS }\end{array}$ \\
\hline A & 73 & $5 \mathrm{~T} / 7 \mathrm{~T}$ \\
B & 92 & $5 \mathrm{~T} / 5 \mathrm{~T}$ \\
C & 89 & $5 \mathrm{~T} / 5 \mathrm{~T}$ \\
$\mathrm{D}$ & 90 & $5 \mathrm{~T} / 5 \mathrm{~T}$ \\
E & 12 & $7 \mathrm{~T} / 7 \mathrm{~T}$ \\
$\mathrm{~F}$ & 14 & $7 \mathrm{~T} / 9 \mathrm{~T}$ \\
$\mathrm{G}$ & 16 & $7 \mathrm{~T} / 7 \mathrm{~T}$ \\
$\mathrm{H}$ & 20 & $7 \mathrm{~T} / 7 \mathrm{~T}$ \\
\hline
\end{tabular}

* Individuals A-H are the same individuals as in Fig. 2, respectively. ₹ SAS, splice acceptor site. The length of polyT tract at the intron 8/exon 9 splice acceptor site of both CFTR alleles are shown. The number in front of " $T$ " indicates the number of consecutive $T$ 's of the polyT tract.

protein levels in bronchial epithelial cells of individuals with very high exon $9^{-}$CFTR mRNA transcript levels are lower than those individuals with low exon $9^{-}$CFTR mRNA transcripts.

In regard to the underlying mechanism for the exon 9 splicing of bronchial epithelial CFTR mRNA transcripts, we noted previously (15) that: $(a)$ there was a polythymidine (polyT) tract at intron 8 /exon 9 splice acceptor site, which contained five, seven, or nine consecutive T's (5T, 7T, or 9T) ending six bases from the start of exon 9 coding sequence; $(b)$ among 24 CFTR alleles of the 12 normal individuals, 21 had 7T, 1 had $9 \mathrm{~T}$, and 2 had $5 \mathrm{~T}$ at the intron 8 /exon 9 splice acceptor site; $(c)$ each of the two individuals with $>50 \%$ bronchial epithelial exon $9^{-}$mRNA transcripts ( 62 and $66 \%$ ) had one CFTR allele containing $5 \mathrm{~T}$ at intron 8 / exon 9 splice acceptor site; and $(d)$ all these 24 CFTR alleles contained complete sequences of exon 9 . Interestingly, in the present study, all three individuals (B-D) with highest bronchial epithelial exon $9^{-}$transcripts (89-92\%) had both CFTR alleles containing 5 T polyT tract at intron 8 /exon 9 splice acceptor site and individual $A$, whose bronchial epithelium contained $73 \%$ exon $9^{-}$CFTR transcripts, had one CFTR allele containing $5 \mathrm{~T}$ and the other CFTR allele containing 7T at intron 8/exon 9 splice acceptor site ( Table II). In contrast, individuals $\mathrm{E}-\mathrm{H}$ all had low percent exon $9^{-}$transcripts and both CFTR alleles of these individuals contained 7T ( seven of eight alleles) or 9T ( one of eight alleles) in this splice acceptor site. None of CFTR alleles of individuals A-H had deletion of exon 9. These observations are consistent with the concept that the $5 \mathrm{~T}$ polyT tract at intron 8 /exon 9 splice acceptor site is a major factor causing alternative exon 9 splicing of CFTR mRNA transcripts.

\section{Acknowledgments}

We would like to thank Milica S. Chernick, National Institute of Diabetes, Digestive and Kidney Disease for performing sweat $\mathrm{Cl}^{-}$tests, and Theresa Raymer for editorial assistance.

This work was supported in part by the Cystic Fibrosis Foundation, Merck Clinician Scientist Award (G. R. Cutting) and National Institute of Diabetes and Digestive and Kidney Diseases (G. R. Cutting). 


\section{References}

1. Boat, T. F., M. J. Welsh, and A. L. Beaudet. 1989. Cystic fibrosis. In The Metabolic Basis of Inherited Disease. C. R. Scriver, A. L. Beaudet, W. S. Sly, and D. Valle, editors. McGraw-Hill Inc., New York. 2649-2680.

2. Welsh, M. J., and R. B. Fick. 1987. Cystic fibrosis. J. Clin. Invest. 80:15231526.

3. Rommens, J. M., M. C. Iannuzzi, B.-S. Kerem, M. L. Drumm, G. Melmer, M. Dean, R. Rozmahel, J. L. Cole, D. Kennedy, N. Hidaka, et al. 1989. Identification of the cystic fibrosis gene: chromosome walking and jumping. Science (Wash. DC). 245:1059-1065.

4. Riordan, J. R., J. M. Rommens, B.-S. Kerem, N. Alon, R. Rozmahel, Z. Grzelczak, J. Zielenski, S. Lok, N. Plavsic, J.-L. Chou, et al. 1989. Identification of the cystic fibrosis gene: cloning and characterization of complementary DNA. Science (Wash. DC). 245:1066-1073.

5. Kerem, B.-S., J. M. Rommens, J. A. Buchanan, D. Markiewicz, T. K. Cox, A. Chakravarti, M. Buchwald, and L.-C. Tsui. 1989. Identification of the cystic fibrosis gene: genetic analysis. Science (Wash. DC). 245:1073-1080.

6. Zielenski, J., R. Rozmahel, D. Bozon, B.-S. Kerem, Z. Grzelczak, J. R. Riordan, J. Rommens, and L.-C. Tsui. 1991. Genomic DNA sequence of the cystic fibrosis transmembrane conductance regulator (CFTR) gene. Genomics. 10:214-228.

7. Hyde, S. C., P. Emsley, M. J. Hartshorn, M. M. Mimmack, U. Gileadi, S. R. Pearce, M. P. Gallagher, D. R. Gill, R. E. Hubbard, and C. F. Higgins. 1990. Structural model of ATP-binding proteins associated with cystic fibrosis, multidrug resistance and bacterial transport. Nature (Lond.). 346:362-365.

8. Cutting, G. R., L. M. Kasch, B. J. Rosenstein, J. Zielenski, L.-C. Tsui, S. E. Antonarakis, and H. H. Kazazian, Jr. 1990. A cluster of cystic fibrosis mutations in the first nucleotide-binding fold of the cystic fibrosis conductance regulator protein. Nature (Lond.). 346:366-369.

9. Kerem, B.-S., J. Zielenski, D. Markiewicz, D. Bozon, E. Gazit, J. Yahav, D. Kenneky, J. R. Riordan, F. S. Collins, J. M. Rommens, and L.-C. Tsui. 1990. Identification of mutations in regions corresponding to the two putative nucleotide (ATP)-binding folds of the cystic fibrosis gene. Proc. Natl. Acad. Sci. USA. 87:8447-8451.

10. Gregory, R. J., D. P. Rich, S. H. Cheng, D. W. Souza, S. Paul, P. Manavalan, M. P. Anderson, M. J. Welsh, and A. E. Smith. 1991. Maturation and function of cystic fibrosis transmembrane conductance regulator variants bearing mutations in putative nucleotide-binding domains 1 and 2. Mol. Cell. Biol. 11:3886-3893.

11. Cheng, S. H., R. J. Gregory, J. Marshall, S. Paul, D. W. Souza, G. A. White, C. R. O'Riordan, and A. E. Smith. 1990. Defective intracellular transport and processing of CFTR is the molecular basis of most cystic fibrosis. Cell. 63:827-834.

12. Anderson, M. P., D. P. Rich, R. J. Gregory, A. E. Smith, and M. J. Welsh. 1991. Generation of cAMP-activated chloride currents by expression of CFTR. Science (Wash. DC). 251:679-682.

13. Walker, J. E., M. Saraste, M. J. Runswick, and N. J. Gay. 1982. Distantly related sequences in the $\alpha$-and $\beta$-subunits of ATP synthase, myosin, kinases and other ATP-requiring enzymes and a common nucleotide binding fold. $E M B O$ (Eur. Mol. Biol. Organ.) J. 1:945-951.

14. Cuppens, H., P. Marynen, C. De Boeck, F. De Baets, E. Eggermont, H. Van den Berghe, and J. J. Cassiman. 1990. A child, homozygous for a stop codon in exon 11, shows milder cystic fibrosis symptoms than her heterozygous nephew. J. Med. Genet. 27:717-719.

15. Chu, C.-S., B. C. Trapnell, J. J. Murtagh, Jr., J. Moss, W. Dalemans, S. Jallat, A. Mercenier, A. Pavirani, J.-P. Lecocq, G. R. Cutting, et al. 1991. Variable deletion of exon 9 coding sequences in cystic fibrosis transmembrane conductance regulator gene mRNA transcripts in normal bronchial epithelium. EMBO (Eur. Mol. Biol. Organ.) J. 10:1355-1363.

16. Davis, P. B., S. Del Rio, J. A. Muntz, and L. Dieckman. 1983. Sweat chloride concentration in adults with pulmonary diseases. Am. Rev. Respir. Dis. 128:34-37.

17. Fulmer, J. D., W. C. Roberts, E. R. Von Gal, and R. G. Crystal. 1977. Small airways in idiopathic pulmonary fibrosis: comparison of morphologic and physiologic observations. J. Clin. Invest. 60:595-610.

18. Saltini, C., A. J. Hance, V. J. Ferrans, F. Basset, P. B. Bitterman, and R. G. Crystal. 1984. Accurate quantification of cells recovered by bronchoalveolar lavage. Am. Rev. Respir. Dis. 130:650-658.

19. Brantly, M. L., J. T. Wittes, C. F. Vogelmeier, R. C. Hubbard, G. A. Fells, and R. G. Crystal. 1991. Use of a highly purified $\alpha_{1}$-antitrypsin standard to establish ranges for the common normal and deficient $\alpha_{1}$-antitrypsin phenotypes. Chest. 100:703-708.
20. Brantly, M. L., L. D. Paul, B. H. Miller, R. T. Falk, M. Wu, and R. G. Crystal. 1988. Clinical features and history of the destructive lung disease associated with alpha-1-antitrypsin deficiency of adults with pulmonary symptoms. Am. Rev. Respir. Dis. 138:327-336.

21. Crystal, R. G., J. D. Fulmer, W. C. Roberts, M. L. Moss, B. R. Line, and H. Y. Reynolds. 1976. Idiopathic pulmonary fibrosis: clinical, histologic, radiographic, physiologic, scintigraphic, cytologic, and biochemical aspects. Ann. Intern. Med. 85:769-788.

22. Saiki, R. K., D. H. Gelfand, S. Stoffel, S. J. Scharf, R. Higuchi, G. T. Horn, K. B. Mullis, and H. A. Erlich. 1988. Primer-directed enzymatic amplification of DNA with a thermostable DNA polymerase. Science (Wash. DC). 239:487-491.

23. Chirgwin, J. M., A. E. Przybyla, R. J. MacDonald, and W. J. Rutter. 1979. Isolation of biologically active ribonucleic acid from sources enriched in ribonuclease. Biochemistry. 18:5294-5299.

24. Trapnell, B. C., P. L. Zeitlin, C.-S. Chu, K. Yoshimura, H. Nakamura, W. B. Guggino, J. Bargon, T. C. Banks, W. Dalemans, A. Pavirani, J.-P. Lecocq, and R. G. Crystal. 1991. Down-regulation of cystic fibrosis gene mRNA transcript levels and induction of the cystic fibrosis chloride secretory phenotype in epithelial cells by phorbol ester. J. Biol. Chem. 266:10319-10323.

25. Ercolani, L., B. Florence, M. Denaro, and M. Alexander. 1988. Isolation and complete sequence of a functional human glyceraldehyde-3-phosphate dehydrogenase gene. J. Biol. Chem. 263:15335-15341.

26. Frizzell, R. A., G. Rechkemmer, and R. L. Shoemaker. 1986. Altered regulation of airway epithelial cell chloride channels in cystic fibrosis. Science (Wash. DC). 233:558-560.

27. Li, M., J. D. McCann, M. P. Anderson, J. P. Clancy, C. M. Liedtke, A. C. Nairn, P. Greengard, and M. J. Welsh. 1989. Regulation of chloride channels by protein kinase $\mathrm{C}$ in normal and cystic fibrosis airway epithelia. Science (Wash. DC). 244:1353-1356.

28. Hwang, T.-C., L. Lu, P. L. Zeitlin, D. C. Gruenert, R. Huganir, and W. B. Guggino. 1989. $\mathrm{Cl}^{-}$channels in $\mathrm{CF}$ : lack of activation by protein kinase $\mathrm{C}$ and cAMP-dependent protein kinase. Science (Wash. DC). 244:1351-1353.

29. Li, M., J. D. McCann, C. M. Liedtke, A. C. Nairn, P. Greengard, and M. J. Welsh. 1988. Cyclic AMP-dependent protein kinase opens chloride channels in normal but not cystic fibrosis airway epithelium. Nature (Lond.). 331:358-360.

30. Welsh, M. J. 1990. Abnormal regulation of ion channels in cystic fibrosis epithelia. FASEB (Fed. Am. Soc. Exp. Biol.) J. 4:2718-2725.

31. Wagner, J. A., A. L. Cozens, H. Schulmans, D. C. Gruenert, L. Stryer, and P. Gardner. 1991. Activation of chloride channels in normal and cystic fibrosis airway epithelial cells by multifunctional calcium/calmodulin-dependent protein kinase. Nature (Lond.). 349:793-796.

32. Anderson, M. P., R. J. Gregory, S. Thompson, D. W. Souza, S. Paul, R. C. Mulligan, A. E. Smith, and M. J. Welsh. 1991. Demonstration that CFTR is a chloride channel by alteration of its anion selectivity. Science (Wash. DC). 253:202-205.

33. Kartner, N., J. W. Hanrahan, T. J. Jensen, A. L. Naismith, S. Sun, C. A. Ackerley, E. F. Reyes, L.-C. Tsui, J. M. Rommens, C. E. Bear, and J. R. Riordan. 1991. Expression of the cystic fibrosis gene in non-epithelial invertebrate cells produces a regulated anion conductance. Cell. 64:681-691.

34. Rich, D. P., R. J. Gregory, M. P. Anderson, P. Manavalan, A. E. Smith, and M. J. Welsh. 1991. Effect of deleting the R domain on CFTR-generated chloride channels. Science (Wash. DC). 253:205-207.

35. Cheng, S. H., D. P. Rich, J. Marshall, R. J. Gregory, M. J. Welsh, and A. E. Smith. 1991. Phosphorylation of the R domain by cAMP-dependent protein kinase regulates the CFTR chloride channel. Cell. 66:1027-1036.

36. Davies, K. 1990. Cystic fibrosis-complementary endeavours. Nature (Lond.). 348:110-111.

37. Cutting, G. R., L. M. Kasch, B. J. Rosenstein, L.-C. Tsui, H. H. Kazazian, Jr., and S. E. Antonarakis. 1990. Two patients with cystic fibrosis, nonsense mutations in each cystic fibrosis gene, and mild pulmonary disease. $N$. Engl. $J$. Med. 323:1685-1689.

38. Yoshimura, K., H. Nakamura, B. C. Trapnell, W. Dalemans, A. Pavirani, J.-P. Lecocq, and R. G. Crystal. 1991. The cystic fibrosis gene has a "housekeeping"-type promoter and is expressed at low levels in cells of epithelial origin. $J$. Biol. Chem. 266:9140-9144.

39. Trapnell, B. C. C.-S. Chu, P. K. Paakko, T. C. Banks, K. Yoshimura, V. J. Ferrans, M. S. Chernick, and R. G. Crystal. 1991. Expression of the cystic fibrosis transmembrane conductance regulator gene in the respiratory tract of normal individuals and individuals with cystic fibrosis. Proc. Natl. Acad. Sci. USA. 88:6565-6569.

40. Johnson, L. G., J. C. Olsen, B. Sarkardi, K. L. Moore, R. Swanstrom, and R. C. Boucher. 1991. Percentage of cells in CF airway epithelia that must be corrected to effect phenotypic restoration of normal function. 1991 North American Cystic Fibrosis Conference, Late-breaking Science Session, 5A. (Abstr.) 